\title{
Incidental imaging finding of chest wall mass
}

\author{
R. N. Patel ${ }^{1}$ • M. P. Kiczek ${ }^{1}$ - B. P. Rubin ${ }^{2}$ C. S. Winalski ${ }^{1,3}$
}

Published online: 3 May 2015

(C) ISS 2015

\section{Incidental imaging finding of chest wall mass}

A 64-year-old male with incidental finding of a right chest wall mass (Figs. 1 and 2).

Fig. 1 a Supine abdominal radiograph, $\mathbf{b}$ coned-down image from the supine abdominal radiograph a

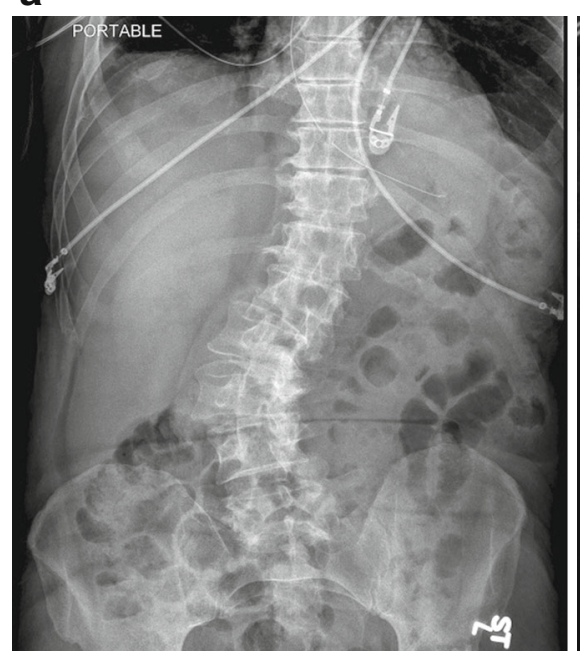

b

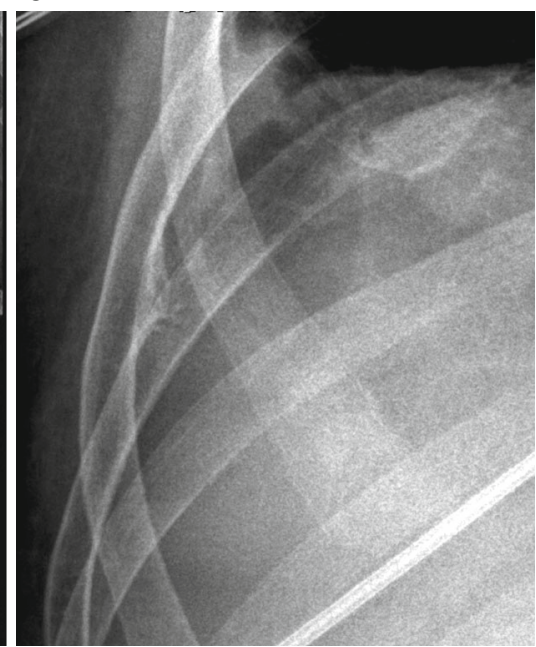

The diagnosis can be found at doi: 10.1007/s00256-015-2148-y

\section{R. N. Patel}

rati.pate13@gmail.com

1 Imaging Institute, Cleveland Clinic, 9500 Euclid Avenue, Cleveland, OH 44195, USA

2 Robert J. Tomsich Pathology \& Laboratory Medicine Institute, Cleveland Clinic, 9500 Euclid Avenue, Cleveland, OH 44195, USA

3 Department of Biomedical Engineering, Lerner Research Institute, Cleveland Clinic, 9500 Euclid Avenue, Cleveland, OH 44195, USA

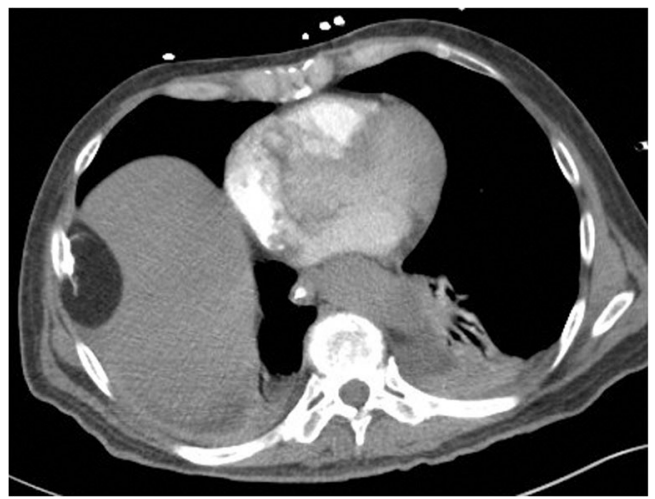

Fig. 2 Post-contrast axial CT of the chest

Conflict of interest The authors declare that they have no conflicts of interest. 